\title{
Effects of plasma concentrations of 5-fluorouracil on long-term survival after treatment with a definitive 5 -fluorouracil/cisplatin-based chemoradiotherapy in Japanese patients with esophageal squamous cell carcinoma
}

\author{
Akiko Kuwahara ${ }^{1,2}$, Motohiro Yamamori 1,2, Kaori Kadoyama ${ }^{2,3}$, Kohshi Nishiguchi $^{2,4}$, Tsutomu Nakamura ${ }^{2}$,
} Ikuya Miki ${ }^{2}$, Takao Tamura², Tatsuya Okuno ${ }^{2}$, Hideaki Omatsu² and Toshiyuki Sakaeda 2,3*

\begin{abstract}
Background: A substantial body of literature has accumulated during the past 20 years showing the plasma concentrations of 5-fluorouracil (5-FU) to correlate with clinical response and/or toxicity in colorectal cancer, and head and neck cancer, but little information is available concerning effects on long-term survival. Here, Japanese patients with esophageal squamous cell carcinoma (ESCC) were followed up for 5 years after treatment with a definitive 5-FU/cisplatin (CDDP)-based chemoradiotherapy (CRT), and the association between prognosis and the plasma concentration of 5-FU was evaluated.

Methods: Forty-nine patients with ESCC, who were treated with a definitive 5-FU/CDDP-based CRT, were enrolled. A course consisted of the continuous infusion of 5 -FU at $400 \mathrm{mg} / \mathrm{m}^{2} /$ day for days $1-5$ and $8-12$, the infusion of CDDP at $40 \mathrm{mg} / \mathrm{m}^{2} /$ day on days 1 and 8, and the radiation at 2 Gy/day on days 1 to 5,8 to 12 , and 15 to 19 , with a second course repeated after a 2-week interval. Plasma concentrations of 5-FU were determined by high performance liquid chromatography at 5:00 PM on days 3, 10, 38 and 45, and at 5:00 AM on days 4, 11, 39 and 46. Results: The overall 5-year survival rate was $42.9 \%$. Age $(P=0.020)$, body weight $(P=0.019)$, and disease stage ( $P$ $=0.048$ ) affected the survival, and the survival depended on the clinical response assessed at 1 month after the treatment $(P=0.001)$. Higher plasma concentrations of 5 - FU resulted in a better clinical response $(P=0.043)$, and trended to prolong survival $(P=0.321)$.

Conclusions: The long-term survival after treatment with a definitive 5-FU/CDDP-based CRT possibly depends on the plasma concentrations of 5-FU, and further clinical studies with a larger number of cases are needed to clarify the relationship between them.
\end{abstract}

Keywords: esophageal squamous cell carcinoma, 5-fluorouracil, plasma concentration, clinical outcome, prognosis

\section{Background}

A clinical report published in 1999, the RTOG (Radiation Therapy Oncology Group) 85-01 trial involving 134 patients with T1-3, N0-1 and M0 esophageal cancer, is of great interest in terms of clinical outcome because it

\footnotetext{
* Correspondence: sakaedat@pharm.kyoto-u.ac.jp

${ }^{2}$ Kobe University Graduate School of Medicine, Kobe 650-0017, Japan

Full list of author information is available at the end of the article
}

demonstrated a 5 -year survival rate of $26 \%$ [1-4]. This treatment consists of a 96-hr-infusion of 5 -fluorouracil (5-FU) at a daily dose of $1,000 \mathrm{mg} / \mathrm{m}^{2} /$ day in weeks 1,5 , 8 and 11, infusion of cisplatin (CDDP) at $75 \mathrm{mg} / \mathrm{m}^{2} /$ day on the first day of weeks $1,5,8$ and 11, and concurrent radiation at 50 Gy in 25 fractions over 5 weeks, without pre- or post-surgical resection. Simultaneously in Japan, another version was proposed by Ohtsu and his coworkers for advanced metastatic esophageal squamous 
cell carcinoma (ESCC) which consists of a 120-hr-infusion of 5 -FU at $400 \mathrm{mg} / \mathrm{m}^{2} /$ day in weeks $1,2,6$ and 7 , infusion of CDDP at $40 \mathrm{mg} / \mathrm{m}^{2} /$ day on the first day of weeks 1, 2, 6 and 7, and concurrent radiation at 60 Gy in 30 fractions over 8 weeks $[5,6]$. Two independent clinical investigations have shown curative potential using this regimen for unresectable ESCC with T4 or M1a [5,6], and a long-term evaluation of efficacy and toxicity with 139 patients resulted in a complete response (CR) rate of $56 \%$, along with a 5 -year survival rate of $29 \%$ [7-9]. Currently, a definitive 5-FU/CDDPbased chemoradiotherapy (CRT) is recognized as one of the most promising treatments for esophageal cancer, but given the extensive inter-individual variation in clinical outcome and severe late toxicities, future improvements will likely require the dose-modification of these regimens, incorporation of a novel anticancer drug, pharmacokinetically guided administration of 5-FU or CDDP, and identification of responders via patient genetic profiling [10].

5-FU exerts its anticancer effects through inhibition of thymidylate synthase and incorporation of its metabolites into RNA and DNA, and has been used widely for the treatment of solid tumors for nearly 50 years [11]. A substantial body of literature has accumulated over the past 20 years showing the plasma concentrations of 5 -FU to correlate with clinical response and/or toxicity in colorectal cancer, and head and neck cancer [12-21]. Although the therapeutic drug monitoring has not been used for chemotherapeutic agents [22,23], the accumulation of data has encouraged us to apply this strategy in the case of 5 -FU [24,25]. There are only 2 reports in which plasma concentrations of 5-FU has been shown to correlate with long-term survival $[16,18]$, but Gamelin and his co-workers conducted a phase III, multicenter, randomized trial in which pharmacokinetically guided administration of 5FU was compared with conventional dosing in patients with metastatic colorectal cancer, and concluded that individual dose adjustments of 5-FU resulted in an improved objective response rate and fewer severe toxicities, and in a trend toward a higher survival rate [21].

A series of studies has been performed to find a marker predictive of clinical response 1 month after or severe toxicities during treatment with a definitive 5FU/CDDP-based CRT in Japanese patients with ESCC [26-31]. Obviously, the final goal of cancer chemotherapy is an improvement in long-term survival, not a short-term clinical response, so parameters predicting prognosis have been absolutely imperative. In this study, patients with ESCC were followed up for 5 years after treatment with a definitive 5-FU/CDDP-based CRT. This is the first report on the effects of plasma concentrations of 5-FU on long-term survival in cases of esophageal cancer.

\section{Methods \\ Patients}

Forty-nine ESCC patients were enrolled in this study based on the following criteria: 1) ESCC treated with a definitive 5-FU/CDDP-based chemoradiotherapy at Kobe University Hospital, Japan, from October, 2003 to June, 2006; 2) clinical stage $\mathrm{T} 1$ to $\mathrm{T} 4$, N0 or N1, and M0 or M1a according to the International Union Against Cancer tumor-node-metastasis (TNM) classification; 3) age less than 85 years; 4) an Eastern Cooperative Oncology Group performance status of 0 to $2 ; 5$ ) adequate bone marrow, renal, and hepatic function; 6) no prior chemotherapy; 7) no severe medical complications; and 8) no other active malignancies (except early cancer). The tumors were histologically confirmed to be primary, and no patients with recurrence were included in this study.

\section{Protocol}

The protocol is presented in Figure 1. A course consisted of the continuous infusion of $5-\mathrm{FU}$ at $400 \mathrm{mg} / \mathrm{m}^{2} /$ day for days 1-5 and 8-12, the infusion of CDDP at 40 $\mathrm{mg} / \mathrm{m}^{2} /$ day on days 1 and 8 , and the radiation at 2 Gy/ day on days 1 to 5,8 to 12 , and 15 to 19 , with a second course repeated after a 2 -week interval $[5,6]$. If disease progression/recurrence was observed, either salvage surgery, endoscopic treatment, or another regimen of chemotherapy was scheduled. This study was conducted with the authorization of the institutional review board and followed the medical research council guidelines of Kobe University. Written informed consent was obtained from all participants prior to enrollment.

\section{Determination of plasma concentrations of 5-FU}

Aliquots $(5 \mathrm{~mL})$ of blood were collected into etylenediaminetetraacetic acid-treated tubes at 5:00 PM on days 3, 10,38 , and 45 , and at 5:00 AM on days 4, 11, 39, and 46 [26-30]. The plasma concentrations of 5-FU were determined by high-performance liquid chromatography as described previously [26-30].

\section{Clinical response}

The clinical response was evaluated as reported previously [5-9]. Briefly, a complete response (CR) was defined as the complete disappearance of all measurable and assessable disease at the first evaluation, which was performed 1 month after the completion of CRT to determine whether the disease had progressed. The clinical response was evaluated by endoscopy and chest and abdominal computed tomography (CT) scans in each course. A CR at the primary site was evaluated by endoscopic examination when all of the following criteria were satisfied on observation of the entire esophagus: 1 ) disappearance of the tumor lesion; 2) disappearance of 


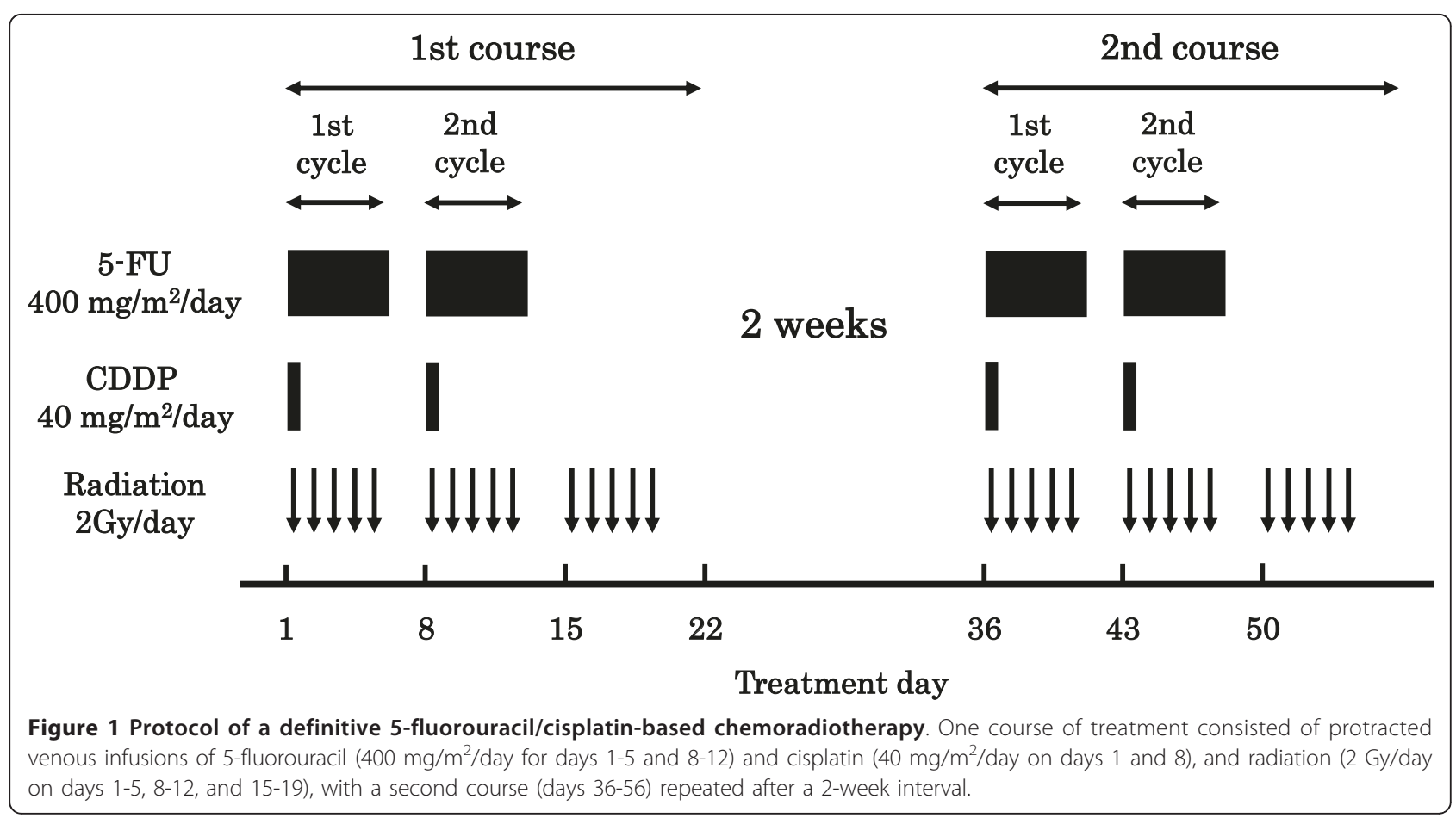

ulceration (slough); and 3) absence of cancer cells in biopsy specimens. If small nodes of $1 \mathrm{~cm}$ or less were detected on CT scans, the recovery was defined as an "uncertain CR" after confirmation of no progression for at least 3 months. An "uncertain CR" was included as a $\mathrm{CR}$ when calculating the $\mathrm{CR}$ rate. When these criteria were not satisfied, a non-CR was assigned. The existence of erosion, a granular protruded lesion, an ulcer scar, and $1.2 \mathrm{w} / \mathrm{v} \%$ iodine/glycerin-voiding lesions did not prevent an evaluation of CR. The evaluations were performed every month for the first 3 months, and when the criteria for CR were not satisfied at 3 months, the result was changed to non-CR. Follow-up evaluations were performed thereafter every 3 months for 3 years by endoscopy and CT scan. After 3 years, patients were seen every 6 months. During the follow-up period, a routine course of physical examinations and clinical laboratory tests was performed to check the patient's health.

\section{Severe acute toxicities}

A definitive 5-FU/CDDP-based CRT is associated with acute toxicities, predominantly leucopenia, stomatitis, and cheilitis [5-9]. Toxicity was evaluated using criteria defined by the Japan Clinical Oncology Group [32]. These criteria were based on the National Cancer Institute Common Toxicity Criteria. Toxicity was assessed on a 2 to 3 day basis during the CRT and subsequent hospitalization period and on every visit after the completion of CRT. Episodes of leucopenia, stomatitis, and cheilitis during the first 2 courses and subsequent 2 weeks (until day 70) were recorded as acute toxicities and those of grade 3 or more as severe acute toxicities.

\section{Survival after treatment with a 5-FU/CDDP-based CRT}

Survival time was defined as the time from treatment initiation to death from any cause or to the last date of confirmation of survival. Survival data were updated on June 25, 2011.

\section{Data analysis and statistics}

All values reported are the mean \pm standard deviation (SD). The unpaired Student's $t$-test/Welch's test or Mann-Whitney's $U$ test was used for two-group comparisons, and AVOVA was for multiple comparisons. Fisher's exact test was also used for the analysis of contingency tables. The difference of overall survival curves was analyzed by Log-rank test. P values of less than 0.05 (two tailed) were considered to be significant.

\section{Results}

Demographic/clinicopathologic characteristics and clinical outcome of 49 Japanese ESCC patients are summarized in Table 1. The 1-year, 2-year, and 5-year survival rates were $71.4 \%, 57.1 \%$, and $42.9 \%$, respectively. The patients who survived 5 years or more were older $(\mathrm{P}=$ $0.020)$ and heavier $(P=0.019)$ than those who lasted less than 5 years. There was a significant difference in disease stage between the 2 groups $(P=0.048)$. The $C R$ rate was $76.2 \%$ for the patients surviving 5 years or 
Table 1 Demographic/clinicopathologic characteristics and clinical outcome after treatment with a definitive 5fluorouracil/cisplatin-based chemoradiotherapy in 49 Japanese patients with esophageal squamous cell carcinoma

\begin{tabular}{|c|c|c|c|c|}
\hline Group & Total & Survival of 5 years or more & Survival of less than 5 years & $P^{\text {a) }}$ \\
\hline $\mathbf{N}$ & 49 & 21 & 28 & \\
\hline \multicolumn{5}{|l|}{ 1) Demographic/clinicopathologic } \\
\hline Age, yr & $64.5 \pm 7.4(48-78)^{b)}$ & $67.3 \pm 5.8(60-78)$ & $62.4 \pm 7.9(48-76)$ & 0.020 \\
\hline Height, cm & $163.5 \pm 6.6(150-180)$ & $161.9 \pm 6.1(150-171)$ & $164.8 \pm 6.8(152-180)$ & 0.125 \\
\hline Weight, kg & $56.1 \pm 9.6(33-79)$ & $59.8 \pm 9.5(40-74)$ & $53.3 \pm 8.9(33-79)$ & 0.019 \\
\hline Male/Female & $46 / 3$ & $20 / 1$ & $26 / 2$ & 1.000 \\
\hline Performance status, 0/1/2/unknown & 24/20/4/1 & $11 / 7 / 2 / 1$ & $13 / 13 / 2 / 0$ & 0.579 \\
\hline Differentiation, well/moderate/poor/unknown & $7 / 28 / 8 / 6$ & $4 / 11 / 3 / 3$ & $3 / 17 / 5 / 3$ & 0.817 \\
\hline $\mathrm{T} 1 / \mathrm{T} 2 / \mathrm{T} 3 / \mathrm{T} 4$ & $16 / 6 / 15 / 12$ & $10 / 2 / 7 / 2$ & $6 / 4 / 8 / 10$ & 0.099 \\
\hline N0/N1 & $22 / 27$ & $13 / 8$ & $9 / 19$ & 0.048 \\
\hline $\mathrm{M} 0 / \mathrm{M} 1 \mathrm{a}^{\mathrm{c}}$ & $41 / 8$ & $20 / 1$ & $21 / 7$ & 0.115 \\
\hline Stage $|/||/| I|/| V$ & $12 / 10 / 19 / 8$ & $7 / 7 / 6 / 1$ & $5 / 3 / 13 / 7$ & 0.048 \\
\hline \multicolumn{5}{|l|}{ 2) Clinical outcome } \\
\hline Complete response & $23(46.9 \%)$ & $16(76.2 \%)$ & 7 (25.0\%) & 0.0005 \\
\hline Grade 3/4 Leucopenia & $21(42.9 \%)$ & 9 (42.9\%) & $12(42.9 \%)$ & 1.000 \\
\hline Grade 3/4 Stomatitis & 7 (14.3\%) & $4(19.0 \%)$ & $3(10.7 \%)$ & 0.443 \\
\hline Grade $3 / 4$ Cheilitis & $8(16.3 \%)$ & $4(19.0 \%)$ & $4(14.3 \%)$ & 0.710 \\
\hline
\end{tabular}

a) Survival of 5 years or more vs. less than 5 years.

b) The values are the mean $\pm S D$, with the range in parentheses.

c) Noncervical primary tumors with positive supraclavicular lymph nodes were defined as M1a.

more, but only $25.0 \%$ for the others $(\mathrm{P}=0.0005)$. No differences were found in the frequency of episodes of severe acute leucopenia, stomatitis, and cheilitis.

Figure 2 shows the association of clinical response with overall survival after the treatment with a definitive 5-FU/CDDP-based CRT in 49 patients with ESCC. The survival depended on the response, i.e., CR or non-CR

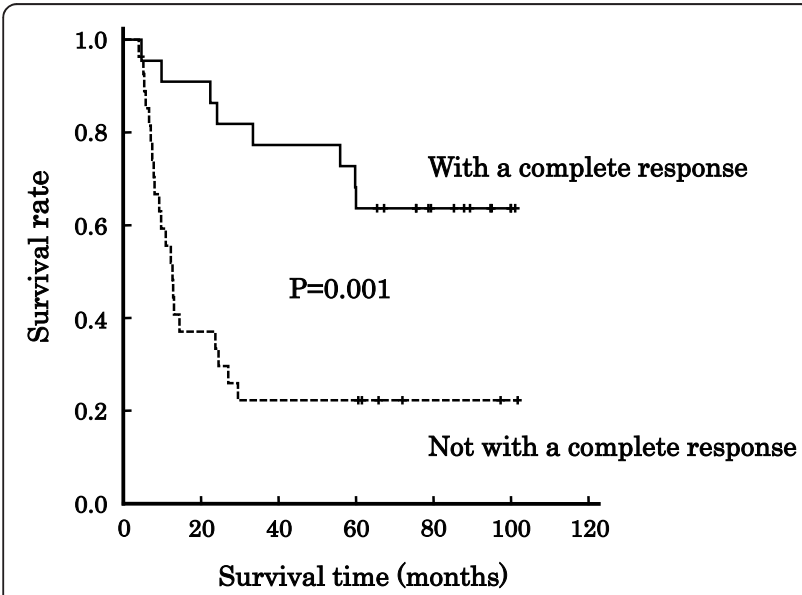

Figure 2 Association of clinical response with overall survival in Japanese patients with esophageal squamous cell carcinoma. Line: patients with a complete response ( $C R, N=23)$, dotted line: patients not with a complete response (non-CR, $N=$ 26). The survival depended on the response ( $P=0.001$, Log-rank test).
( $P=0.001$, Log-rank test). The plasma concentrations of 5 -FU in the patients with a survival time of 5 years or more and with less than 5 years are indicated in Table 2. There was no difference of the 8-point average values of plasma concentrations of 5-FU between the 2 groups $(\mathrm{P}=0.536)$, although the clinical response depended on; $0.124 \pm 0.036 \mu \mathrm{g} / \mathrm{mL}$ for CR, $0.105 \pm 0.030 \mu \mathrm{g} / \mathrm{mL}$ for non-CR $(\mathrm{P}=0.043)$. Figure 3 shows the association of the 8 -point average value with overall survival. The patients were divided into 2 groups based on an overall average of $0.114 \mu \mathrm{g} / \mathrm{mL}$, and again the effect on overall survival was not confirm $(\mathrm{P}=0.321$, Log-rank test). The plasma concentrations of 5 -FU in the patients with $\mathrm{CR}$, but a survival period of less than 5 years, are listed in Table 3. The 8-point average of the concentrations tended to be higher than other subgroups $(\mathrm{P}=0.226$ ).

\section{Discussion}

Originally, 5-FU was administered alone as a bolus, but more recently, it is being administered with biomodulating agents and/or through continuous infusion [11,33]. Because of the preclinical evidence that increased exposure to 5-FU improves its cytotoxic activity and the fact that 5-FU has a short half-life in plasma, continuous infusion has been proposed to increase the percentage of tumor cells exposed to 5-FU [33]. These regimens have resulted in improvements in response rates with improved safety profiles in clinical studies [33]. At present, one of the most important factors complicating the clinical use of 
Table 2 Plasma concentrations of 5-fluorouracil $(\mu \mathrm{g} / \mathrm{mL})$ during a definitive 5 -fluorouracil/cisplatin-based chemoradiotherapy in 49 Japanese patients with esophageal squamous cell carcinoma

\begin{tabular}{|c|c|c|c|c|c|}
\hline \multicolumn{2}{|l|}{ Group } & \multirow{2}{*}{$\begin{array}{c}\text { Total } \\
49\end{array}$} & \multirow{2}{*}{$\begin{array}{l}\text { Survival of } 5 \text { years or more } \\
21\end{array}$} & \multirow{2}{*}{$\begin{array}{l}\text { Survival of less than } 5 \text { years } \\
28\end{array}$} & \multirow[t]{2}{*}{$P^{\text {a) }}$} \\
\hline $\mathrm{N}$ & & & & & \\
\hline \multirow[t]{2}{*}{ 1st cycle/1st course } & Day 3, PM 5:00 & $0.109 \pm 0.060$ & $0.122 \pm 0.080$ & $0.100 \pm 0.041$ & 0.294 \\
\hline & Day 4, AM 5:00 & $0.076 \pm 0.040$ & $0.088 \pm 0.044$ & $0.068 \pm 0.036$ & 0.097 \\
\hline \multirow[t]{2}{*}{ 2nd cycle/1st course } & Day 10, PM 5:00 & $0.150 \pm 0.074$ & $0.137 \pm 0.071$ & $0.158 \pm 0.077$ & 0.357 \\
\hline & Day 11, AM 5:00 & $0.134 \pm 0.047$ & $0.132 \pm 0.048$ & $0.136 \pm 0.047$ & 0.798 \\
\hline \multirow[t]{2}{*}{ 1st cycle/2nd course } & Day 38, PM 5:00 & $0.102 \pm 0.056$ & $0.097 \pm 0.067$ & $0.105 \pm 0.049$ & 0.676 \\
\hline & Day 39, AM 5:00 & $0.076 \pm 0.041$ & $0.077 \pm 0.042$ & $0.076 \pm 0.042$ & 0.897 \\
\hline \multirow[t]{2}{*}{ 2nd cycle/2nd course } & Day 45, PM 5:00 & $0.146 \pm 0.080$ & $0.158 \pm 0.101$ & $0.136 \pm 0.059$ & 0.364 \\
\hline & Day 46, AM 5:00 & $0.119 \pm 0.047$ & $0.126 \pm 0.036$ & $0.114 \pm 0.054$ & 0.399 \\
\hline \multicolumn{2}{|c|}{ Average of 8 sampling points } & $0.114 \pm 0.034$ & $0.118 \pm 0.036$ & $0.112 \pm 0.032$ & 0.536 \\
\hline
\end{tabular}

a) Survival of 5 years or more vs. less than 5 years.

5-FU is extensive inter- and/or intra-individual variability in pharmacokinetics, when doses are calculated based on body surface area $[24,25]$. There is a need to individualize 5 -FU dosing, and the shift from a bolus to continuous infusion has created better conditions for dose management $[24,25]$. Given that the plasma concentration of, or systemic exposure to, 5 -FU has been shown to correlate with the response rate or the rate of adverse effects in patients with advanced colorectal cancer and head and neck cancer [12-21], pharmacokinetically guided dose adjustment has attracted attention [24,25].

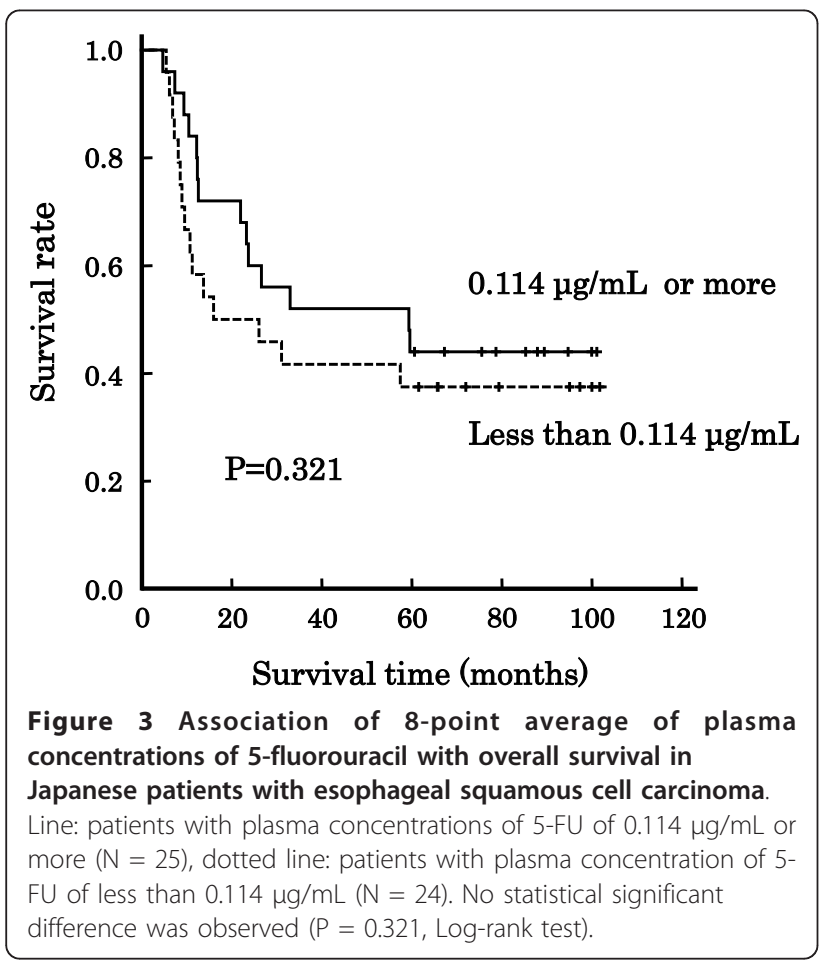

To our knowledge, however, there are only 2 reports in which plasma concentrations of 5 -FU were proven to correlate with long-term survival $[16,18]$. Milano et al. examined patients with head and neck cancer [16], and Di Paolo et al. studied patients with colorectal cancer [18], and both found that the AUC values of 5-FU were significantly correlated with survival. Recently, Gamelin and his co-workers compared pharmacokinetically guided administration of 5-FU with conventional dosing in patients with metastatic colorectal cancer, and found that individual dose adjustments of 5-FU resulted in an improved objective response rate, and in a trend toward a higher survival rate [21].

In this study, we have followed up Japanese patients with ESCC for 5 years after treatment with a definitive 5-FU/CDDP-based CRT. Age $(P=0.020)$, body weight $(P=0.019)$, and disease stage $(P=0.048)$ affected the long-term survival, and the survival depended on the clinical response assessed at 1 month after the treatment, i.e., $\mathrm{CR}$ or non-CR ( $\mathrm{P}=0.001$, Figure 2$)$. The clinical response was determined by the 8-point average values of plasma concentrations of 5 -FU; $0.124 \pm 0.036$ $\mu \mathrm{g} / \mathrm{mL}$ for the patients with $\mathrm{CR}$, and $0.105 \pm 0.030 \mu \mathrm{g} /$ $\mathrm{mL}$ for those with non-CR $(\mathrm{P}=0.043)$, and therefore the survival must be associated with the concentrations. However, the concentrations were not high enough to affect long-term survival ( $\mathrm{P}=0.321$, Figure 3$)$. This is presumably due to low number of patients $(\mathrm{N}=49)$, and further clinical studies with a larger number of cases are needed to clarify the effect on long-term survival.

A subgroup analysis suggested plasma concentrations of 5 -FU to be higher in the patients with CR, but a survival period of less than 5 years, but there was no statistical significance (Table 3). Death from esophageal cancer often occurs in non-CR cases or in recurrent cases. However, the reports indicated severe late toxic 
Table 3 Plasma concentrations of 5-fluorouracil $(\mu \mathrm{g} / \mathrm{mL})$ during a definitive 5 -fluorouracil/cisplatin-based chemoradiotherapy in the patients with a complete response, but survival of less than 5 years

\begin{tabular}{lccccc}
\hline & \multicolumn{2}{c}{ Survival of $\mathbf{5}$ years or more } & \multicolumn{2}{c}{ Survival of less than $\mathbf{5}$ years } \\
\cline { 2 - 6 } $\mathbf{N}$ & $\mathbf{C R}{ }^{\text {a) }}$ & Non-CR & CR & Non-CR & $\mathbf{2 1}$ \\
\hline Average of 8 sampling points & $\mathbf{1 6}$ & $\mathbf{5}$ & $\mathbf{7}$ & $0.131 \pm 0.046$ & $0.105 \pm 0.024$ \\
\hline
\end{tabular}

a) Complete response

b) Assessed by ANOVA

effects, such as myocardial infarction, pericardial effusion, and pleural effusion, in patients after a definitive 5-FU/CDDP-based CRT, especially in cases of extensive radiation $[8,9]$. Here, 2-5 of 49 patients seemed to have died from late toxicity. This might affect the association of the plasma concentrations of 5-FU with long-term survival.

\section{Conclusions}

Japanese ESCC patients were followed up for 5 years after treatment with a definitive 5-FU/CDDP-based CRT, and the association between prognosis and the plasma concentration of 5-FU was evaluated. Age, body weight, and disease stage affected the log-term survival, and the survival depended on the clinical response assessed at 1 month after the treatment. Higher plasma concentrations of 5 -FU resulted in a better clinical response, and tended to prolong survival. Further clinical studies with a larger number of cases are needed to clarify the effect on long-term survival.

\section{Acknowledgements}

This work was supported in part by a Grant-in-Aid for Scientific Research and Service Innovation Program from the Ministry of Education, Culture, Sports, Science and Technology of Japan.

\section{Author details}

'School of Pharmacy and Pharmaceutical Sciences, Mukogawa Women's University, Nishinomiya 663-8179, Japan. ${ }^{2}$ Kobe University Graduate School of Medicine, Kobe 650-0017, Japan. ${ }^{3}$ Graduate School of Pharmaceutical Sciences, Kyoto University, Kyoto 606-8501, Japan. ${ }^{4}$ Faculty of Pharmaceutical Sciences, Kyoto Pharmaceutical University, Kyoto 607-8414, Japan.

\section{Authors' contributions}

AK, TT and TS conceived, designed and coordinated the study. IM, TT, TO and $\mathrm{HO}$ evaluated the clinical outcome. TN and IM determined the plasma concentrations of 5-FU. AK, MY, KK and KN carried out the data management and statistical analysis. AK and TS prepared the manuscript. All authors read and approved the final manuscript.

\section{Competing interests}

The author declares that they have no competing interests.

Received: 10 August 2011 Accepted: 5 October 2011

Published: 5 October 2011

\section{References}

1. Cooper JS, Guo MD, Herskovic A, Macdonald JS, Martenson JA Jr, AlSarraf M, Byhardt R, Russell AH, Beitler JJ, Spencer S, Asbell SO, Graham MV, Leichman LL: Chemoradiotherapy of locally advanced esophageal cancer: long-term follow-up of a prospective randomized trial (RTOG 85-01). Radiation Therapy Oncology Group. JAMA 1999, 281:1623-1627.

2. Herskovic A, Martz K, al-Sarraf M, Leichman L, Brindle J, Vaitkevicius V, Cooper J, Byhardt R, Davis L, Emami B: Combined chemotherapy and radiotherapy compared with radiotherapy alone in patients with cancer of the esophagus. N Engl J Med 1992, 326:1593-1598.

3. al-Sarraf M, Martz K, Herskovic A, Leichman L, Brindle JS, Vaitkevicius VK, Cooper J, Byhardt R, Davis L, Emami B: Progress report of combined chemoradiotherapy versus radiotherapy alone in patients with esophageal cancer: an intergroup study. J Clin Oncol 1997, 15:277-284.

4. Begg C, Cho M, Eastwood S, Horton R, Moher D, Olkin I, Pitkin R, Rennie D, Schulz KF, Simel D, Stroup DF: Improving the quality of reporting of randomized controlled trials. The CONSORT statement. JAMA 1996, 276:637-639.

5. Ohtsu A, Boku N, Muro K, Chin K, Muto M, Yoshida S, Satake M, Ishikura S, Ogino T, Miyata Y, Seki S, Kaneko K, Nakamura A: Definitive chemoradiotherapy for T4 and/or M1 lymph node squamous cell carcinoma of the esophagus. J Clin Oncol 1999, 17:2915-2921.

6. Kaneko K, Ito H, Konishi K, Kurahashi T, Ito T, Katagiri A, Yamamoto T, Kitahara T, Mizutani Y, Ohtsu A, Mitamura K: Definitive chemoradiotherapy for patients with malignant stricture due to T3 or T4 squamous cell carcinoma of the oesophagus. Br J Cancer 2003, 88:18-24.

7. Tahara M, Ohtsu A, Hironaka S, Boku N, Ishikura S, Miyata Y, Ogino T, Yoshida S: Clinical impact of criteria for complete response (CR) of primary site to treatment of esophageal cancer. Jpn J Clin Oncol 2005, 35:316-323.

8. Ishikura S, Nihei K, Ohtsu A, Boku N, Hironaka S, Mera K, Muto M, Ogino T, Yoshida S: Long-term toxicity after definitive chemoradiotherapy for squamous cell carcinoma of the thoracic esophagus. J Clin Oncol 2003, 21:2697-2702.

9. Kumekawa $Y$, Kaneko K, Ito H, Kurahashi T, Konishi K, Katagiri A, Yamamoto T, Kuwahara M, Kubota Y, Muramoto T, Mizutani Y, Imawari M: Late toxicity in complete response cases after definitive chemoradiotherapy for esophageal squamous cell carcinoma. $\lrcorner$ Gastroenterol 2006, 41:425-432

10. Sakaeda T, Yamamori M, Kuwahara A, Nishiguchi K: Pharmacokinetics and pharmacogenomics in esophageal cancer chemoradiotherapy. Adv Drug Deliv Rev 2009, 61:388-401.

11. Longley DB, Harkin DP, Johnston PG: 5-Fluorouracil: mechanisms of action and clinical strategies. Nat Rev Cancer 2003, 3:330-338.

12. Gamelin E, Boisdron-Celle M, Delva R, Regimbeau C, Cailleux PE, Alleaume C, Maillet ML, Goudier MJ, Sire M, Person-Joly MC, Maigre M, Maillart P, Fety R, Burtin P, Lortholary A, Dumesnil Y, Picon L, Geslin J, Gesta P, Danquechin-Dorval E, Larra F, Robert J: Long-term weekly treatment of colorectal metastatic cancer with fluorouracil and leucovorin: results of a multicentric prospective trial of fluorouracil dosage optimization by pharmacokinetic monitoring in 152 patients. $J$ Clin Oncol 1998, 16:1470-1478.

13. Gamelin EC, Danquechin-Dorval EM, Dumesnil YF, Maillart PJ, Goudier MJ, Burtin PC, Delva RG, Lortholary AH, Gesta PH, Larra FG: Relationship between 5-fluorouracil (5-FU) dose intensity and therapeutic response in patients with advanced colorectal cancer receiving infusional therapy containing 5-FU. Cancer 1996, 77:441-451.

14. Vokes EE, Mick R, Kies MS, Dolan ME, Malone D, Athanasiadis I, Haraf DJ, Kozloff M, Weichselbaum RR, Ratain MJ: Pharmacodynamics of fluorouracil-based induction chemotherapy in advanced head and neck cancer. J Clin Oncol 1996, 14:1663-1671.

15. Ychou M, Duffour J, Kramar A, Debrigode C, Gourgou S, Bressolle F, Pinguet F: Individual 5-FU dose adaptation in metastatic colorectal 
cancer: results of a phase II study using a bimonthly pharmacokinetically intensified LV5FU2 regimen. Cancer Chemother Pharmacol 2003, 52:282-290.

16. Milano G, Etienne MC, Renée N, Thyss A, Schneider M, Ramaioli A, Demard F: Relationship between fluorouracil systemic exposure and tumor response and patient survival. J Clin Oncol 1994, 12:1291-1295.

17. Fety R, Rolland F, Barberi-Heyob M, Hardouin A, Campion L, Conroy T, Merlin JL, Rivière A, Perrocheau G, Etienne MC, Milano G: Clinical impact of pharmacokinetically-guided dose adaptation of 5-fluorouracil: results from a multicentric randomized trial in patients with locally advanced head and neck carcinomas. Clin Cancer Res 1998, 4:2039-2045.

18. Di Paolo A, Lencioni M, Amatori F, Di Donato S, Bocci G, Orlandini C, Lastella M, Federici F, lannopollo M, Falcone A, Ricci S, Del Tacca M, Danesi R: 5 -fluorouracil pharmacokinetics predicts disease-free survival in patients administered adjuvant chemotherapy for colorectal cancer. Clin Cancer Res 2008, 14:2749-2755.

19. Beneton M, Chapet S, Blasco H, Giraudeau B, Boisdron-Celle M, DeporteFety R, Denis F, Narcisso B, Calais G, Le Guellec C: Relationship between 5fluorouracil exposure and outcome in patients receiving continuous venous infusion with or without concomitant radiotherapy. $\mathrm{Br} J$ Clin Pharmacol 2007, 64:613-621.

20. Bocci G, Barbara C, Vannozzi F, Di Paolo A, Melosi A, Barsanti G, Allegrini G, Falcone A, Del Tacca M, Danesi R: A pharmacokinetic-based test to prevent severe 5-fluorouracil toxicity. Clin Pharmacol Ther 2006, 80:384-395.

21. Gamelin E, Delva R, Jacob J, Merrouche Y, Raoul JL, Pezet D, Dorval E, Piot G, Morel A, Boisdron-Celle M: Individual fluorouracil dose adjustment based on pharmacokinetic follow-up compared with conventional dosage: results of a multicenter randomized trial of patients with metastatic colorectal cancer. J Clin Oncol 2008, 26:2099-2105

22. de Jonge ME, Huitema AD, Schellens JH, Rodenhuis S, Beijnen JH: Individualised cancer chemotherapy: strategies and performance of prospective studies on therapeutic drug monitoring with dose adaptation: a review. Clin Pharmacokinet 2005, 44:147-173.

23. Alnaim $L$ : Therapeutic drug monitoring of cancer chemotherapy. J Oncol Pharm Pract 2007, 13:207-221.

24. Ploylearmsaeng SA, Fuhr U, Jetter A: How may anticancer chemotherapy with fluorouracil be individualised? Clin Pharmacokinet 2006, 45:567-592.

25. Saif MW, Choma A, Salamone SJ, Chu E: Pharmacokinetically guided dose adjustment of 5-fluorouracil: a rational approach to improving therapeutic outcomes. J Natl Cancer Inst 2009, 101:1543-1552.

26. Miki I, Tamura T, Nakamura T, Makimoto H, Hamana N, Uchiyama $H_{\text {, }}$ Shirasaka D, Morita Y, Yamada H, Aoyama N, Sakaeda T, Okumura K, Kasuga M: Circadian variability of pharmacokinetics of 5 -fluorouracil and CLOCK T3111C genetic polymorphism in patients with esophageal carcinoma. Ther Drug Monit 2005, 27:369-374.

27. Okuno T, Tamura T, Yamamori M, Chayahara N, Yamada T, Miki I, Okamura N, Kadowaki Y, Shirasaka D, Aoyama N, Nakamura T, Okumura K, Azuma T, Kasuga M, Sakaeda T: Favorable genetic polymorphisms predictive of clinical outcome of chemoradiotherapy for stage II/III esophageal squamous cell carcinoma in Japanese. Am J Clin Oncol 2007, 30:252-257.

28. Sakaeda T, Yamamori M, Kuwahara A, Hiroe S, Nakamura T, Okumura K, Okuno T, Miki I, Chayahara N, Okamura N, Tamura T: VEGF G-1154A is predictive of severe acute toxicities during chemoradiotherapy for esophageal squamous cell carcinoma in Japanese patients. Ther Drug Monit 2008, 30:497-503.

29. Kuwahara A, Yamamori M, Nishiguchi K, Okuno T, Chayahara N, Miki I Tamura T, Inokuma T, Takemoto Y, Nakamura T, Kataoka K, Sakaeda T: Replacement of cisplatin with nedaplatin in a definitive 5-fluorouracil/ cisplatin-based chemoradiotherapy in Japanese patients with esophageal squamous cell carcinoma. Int J Med Sci 2009, 6:305-311.

30. Kuwahara A, Yamamori M, Nishiguchi K, Okuno T, Chayahara N, Miki I, Tamura T, Kadoyama K, Inokuma T, Takemoto Y, Nakamura T, Kataoka K, Sakaeda T: Effect of dose-escalation of 5-fluorouracil on circadian variability of its pharmacokinetics in Japanese patients with Stage III/IVa esophageal squamous cell carcinoma. Int J Med Sci 2010, 7:48-54.

31. Kuwahara A, Yamamori M, Fujita M, Okuno T, Tamura T, Kadoyama K, Okamura N, Nakamura T, Sakaeda T: TNFRSF1B A1466G genotype is predictive of clinical efficacy after treatment with a definitive 5fluorouracil/cisplatin-based chemoradiotherapy in Japanese patients with esophageal squamous cell carcinoma. J Exp Clin Cancer Res 2010, 29:100.

32. Tobinai K, Kohno A, Shimada Y, Watanabe T, Tamura T, Takeyama K, Narabayashi M, Fukutomi T, Kondo H, Shimoyama M, Suemasu K, MembersMembers of the Clinical Trial Review Committee of the Japan Clinical Oncology Group: Toxicity Grading Criteria of the Japan Clinical Oncology Group. Jpn J Clin Oncol 1993, 23:250-257.

33. Highlights from: 5-Fluorouracil drug management pharmacokinetics and pharmacogenomics workshop; Orlando, Florida; January 2007. Clin Colorectal Cancer 2007, 6:407-422.

doi:10.1186/1756-9966-30-94

Cite this article as: Kuwahara et al:: Effects of plasma concentrations of 5 -fluorouracil on long-term survival after treatment with a definitive 5 fluorouracil/cisplatin-based chemoradiotherapy in Japanese patients with esophageal squamous cell carcinoma. Journal of Experimental \& Clinical Cancer Research 2011 30:94

\section{Submit your next manuscript to BioMed Central and take full advantage of:}

- Convenient online submission

- Thorough peer review

- No space constraints or color figure charges

- Immediate publication on acceptance

- Inclusion in PubMed, CAS, Scopus and Google Scholar

- Research which is freely available for redistribution
Biomed Central 